\title{
Numinosity and Adaptation to Stress: The Role of Religiosity, Spirituality and Religious Coping in Adaptation to Significant Life Events
}

\author{
Thomas K. Swisher ${ }^{1}$, J.D., Ph.D. \\ ${ }^{1}$ Stevenson University, Stevenson, Maryland, USA \\ Correspondence: Thomas K. Swisher, Stevenson University, Stevenson, Maryland, USA
}

Received: February 2, 2015

Accepted: February 16, 2015

Available online: February 25, 2015

doi:10.11114/ijsss.v3i2.661

URL: http://dx.doi.org/10.11114/ijsss.v3i2.661

\begin{abstract}
The objectives of this study were to examine what role the numinous traits of spirituality, religiosity and religious coping play in one's adaptation to stress associated with divorce, above and beyond the predictive role of the robust construct called personality. Using scores from instruments measuring the above referenced domains from participants who had recently experienced a separation or divorce $(\mathrm{N}=509)$, this study employed correlational statistics and multiple regression analysis to assess the unique contributions which each domain made to the variance in adaptation to stress. This study elucidates the contributions made by numinous constructs (above that of personality) to one's adaptation to stress. Results indicated that spirituality, religiosity, and religious coping produced significant contributions to the variance in adaptation to stress over personality. This suggests that these constructs are important considerations for counselors and their clients who are struggling with stressful events like marital separation and divorce.
\end{abstract}

Keywords: resilience, coping, adaptation to stress, stress related growth, personality, spirituality, religiosity, religious coping, numinous, divorce, marital disruption

In the United States and numerous European countries, divorce rates are relatively high. Divorce is a social and personal phenomenon, the incidence of which is higher in countries and regions exhibiting elevated levels of social-economic indexes such as literacy rates, education, and gender equality (Musai, 2011). This phenomenon is not restricted to western nations, however. In India, for example, a nation which reports one of the lowest divorce rates in the world, there are areas in which divorce rates are climbing exponentially (Premsingh \& Philip, 2014). According to Premsingh and Philip (2014) in Kerala, India, where literacy rates are reported to be high and gender equality is an important community aspiration, the number of divorce filings in family courts nearly tripled between 2005 and 2011.

Divorce has been categorized as a major life stressor, a crisis that brings with it a source of traumatic and intense stress (Tashiro, Frazier, \& Berman, 2006). Studies have demonstrated that divorce can impact one's susceptibility to both mental and physical dysfunction. Separation from a spouse is associated with depression, anxiety, and feelings of rejection, failure, abandonment, and helplessness (Krumrei, Mahoney, \& Pargament, 2011). Stressful life events (such as divorce, bereavement, and job loss) require a significant life readjustment. Little, however, has been reported on the positive and transformative aspects of divorce. Opportunities may exist for growth and development.

Studies have begun to produce evidence that positive responses to separation and divorce are possible (Tashiro, et al., 2006; Kulik \& Heine-Cohen, 2011). Such positive responses have been shown to include relief, personal growth, and enhanced self-esteem (Krumrei et al., 2011). The current study focuses on the roles that the numinous constructs of spirituality, religiosity, and religious coping play in one's positive adaptation to stress associated with separation and divorce. It was hypothesized that individuals who rated higher in measurements of spirituality and religiosity would demonstrate higher levels of positive adaptation to divorce and that those who employed positive religious coping mechanisms over negative religious coping modalities would also report higher levels of positive adaptation.

\section{Spirituality, Religiosity, and Adaptation to Stress}

Spirituality is considered to be a complex, multifaceted construct that manifests itself through an individual's behavior, beliefs, and experience (Miller \& Thoresen, 2003). Spirituality functions at several levels of the stress and coping process including beliefs and values; primary and secondary appraisals such as God attributions; coping behavior such as prayer, fasting, and repentance; coping resources such as connection to nature and community support; and meaning-making such as spiritual reappraisal, re-interpretation of religious literature, and revised application of 
religious tenets (Dein, Cook, \& Koenig, 2012). Spiritual beliefs operate as a contextual framework orienting individuals in their interpretation, comprehension, and reaction to life experiences (Park, 2005). Beliefs help the individual construct meaning out of suffering and provide for a more hopeful and optimistic attitude (Wong, 2010). Beliefs also facilitate active attitudes toward coping and a strengthening of social support in response to stress (Schweitzer, Greenslade, \& Kagee, 2007).

Spirituality and religion function at the level of meaning, (Wong, 2010). The process of meaning-making is often viewed as synonymous with "spirituality" (Mazzotti, Mazzuca, Sebastiani, Scoppola, \& Marchetti, 2011). A stressful event can be reframed as a spiritual opportunity that offers benefits and a chance to gain insights about life (Hodge, 2005). The ability to make meaning when faced with a stressful event often promotes successful coping, adaptation, and well-being (Tedeschi \& Calhoun, 2004). The inability to find meaning, on the other hand, is related to psychological distress, doubt, and uncertainty, which in turn can lead to inactivity and the inhibition of effective coping behaviors (Pienaar, 2008).

\section{Religious Coping and Adaptation to Stress}

There has been a rise in the investigation and study of religious coping as it relates to stressful events in life. In an attempt to capture measurements of religious coping, Pargament distinguished between positive and negative religious coping methods (Pargament, Feuille, \& Burdzy, 2011). He postulated that positive religious coping methods derive from a secure relationship with God, a sense of spirituality, a belief that there is meaning to be found in life, and a sense of spiritual connectedness to others. Negative religious coping methods, according to Pargament, et al. (2011), derive from a general religious orientation which is in tension and turmoil, marked by a shaky relationship with a higher power, a tenuous and ominous view of the world, and a religious struggle in the search for significance. Examples of positive religious coping include benevolent religious appraisals of negative situations, collaborative religious coping, seeking spiritual support from a higher power, seeking support from clergy or congregation members, religious helping of others, and religious forgiveness. Negative religious coping examples include questioning the powers of God, expressions of anger toward God, expression of discontent with one's clergy or congregation, punitive religious appraisal of negative situations, and demonic religious appraisals (Pargament, et al., 2011).

Life satisfaction and quality of life have been associated with positive religious coping (Lee, Nezu \& Nezu, 2014). Furthermore, studies have demonstrated that religious coping methods add unique variance to the prediction of well-being above the effects of non-religious coping (Abu-Raiya \& Pargament, 2014). It should be noted, however, that the use of religious coping among different populations varies widely and is often influenced by the characteristics of the sample and the type of stressor being investigated (Abu-Raiya \& Pargament, 2014).

\section{Method}

\subsection{Participants}

The participants were 573 divorce litigants who had been parties to divorce pleadings in the Circuit Court for Howard County, Maryland. Data from 64 subjects who failed to provide complete responses were eliminated leaving 509 subjects whose responses were included in the analyses (356 women, 153 men). The sample was $62 \%$ women and $27 \%$ men, with $11 \%$ not indicating gender. The sample was 51\% Caucasian, 6\% African American, 2\% Hispanic, $1 \%$ Asian, 30\% other, and $10 \%$ not indicating ethnic background. Percentages of the sample reporting having acquired a Ph.D. was $14 \%$, a Master's degree was $28 \%$, a college degree was $33 \%$, a high school degree or GED was $23 \%$, and $2 \%$ reported no high school degree.

\section{Measures}

\subsection{Positive Adaptation to Stress}

In order to facilitate analyses and provide efficiency in interpreting results, a composite measure of adaptation to stress was computed (hereinafter referred to as "Total Adaptation to Stress" or "TAS"). The three dimensions which form the composite, namely: growth related stress, satisfaction with life, and hope are inter-related and speak to a person's ability to thrive (Tashiro et al., 2006). Creation of this composite measure was intended to capture an outcome dimension that appreciates the multi-dimensional impact that divorce has on people's lives and to provide a comprehensive sampling of the different domains that contribute to that thriving. Affective well-being in the form of satisfaction with life (Diener, Emmons, Larsen, and Griffin, 1985), hope (Snyder, et al. 1996), and growth capacities (Tashiro et al., 2006), are 3 dimensions selected to create a composite outcome variable which speaks to the overall ability of individuals to provide a resilient adaptive response to marital disruption and divorce.

The outcome variable, total adaptation to stress (TAS) was created by standardizing scores from responses to the Revised Stress Related Growth Scale, the Satisfaction with Life Scale, and the Hope Scale and adding them together. A Cronbach alpha of .58 for this composite indicated that the dimensions do have commonality with each other but are not redundant 
(Finn \& Wang, 2014). In this study, these three measures were all significantly, positively inter-correlated (mean $\mathrm{r}=.32$ ).

\subsection{Revised Measures for Stress-Related Growth (RMSRG).}

Developed by Roesch, Rowley, and Vaughn (2004), the RMSRG contains 29 items and three subscales assessing rational/mature thinking, affective/emotional growth, and religious/spiritual growth. This instrument is revised from a version by Park, Cohen, and Murch after examining the factorial validity and dimensionality of the Stress-Related Growth Scale. Evidence for both the reliability and validity (Park, 2005) of the measure have been provided elsewhere within the stress and coping literature. See Roesch et al. (2004) for a fuller discussion.

\subsection{The Satisfaction with Life Scale (SWLS).}

Developed by Diener, et al. (1985), this scale was designed to measure the global life satisfaction component of subjective well-being. This 7-point Likert-like scale contained 5 items including: In most ways my life is close to my ideal; The conditions of my life are excellent; I am satisfied with my life; So far I have gotten the important things I want in life; and, If I could live my life over, I would change almost nothing. The SWLS is the most commonly used measure of life satisfaction worldwide and shows good psychometric properties including validity, internal consistency, test-retest reliability, and adequate invariance across gender and age (Diener, et al., 1985).

\subsection{The State Hope Scale (SHS).}

This Likert-like scale contains 6 items including: "If I should find myself in a jam, I could think of many ways to get out of it"; "At the present time, I am energetically pursuing my goals"; "There are lots of ways around any problem that I am facing now"; "Right now I see myself as being pretty successful"; "I can think of many ways to reach my current goals"; and, "I am meeting the goals that I have set for myself". For results confirming validity and reliability of scores, see Snyder, et al. (1996).

\subsection{The Bi-Polar Adjective Rating Scale (BARS).}

This scale contains 80 bipolar items devised by McCrae and Costa (1987) and based on 40 item adjective pairs. A bipolar scale is a particular type of rating instrument characterized by a continuum between two opposite end points or, in this case, adjectives. The adjective pairs contained in this measurement have been shown to be a valuable assessment tool for measuring the FFM of personality (McCrae \& Costa, 1987). The BARS captures the five major dimensions of personality: Neuroticism, Extraversion, Openness, Agreeableness, and Conscientiousness.

\subsection{The Brief RCOPE.}

Developed by Pargament, the Brief RCOPE consist of seven positive coping items and seven negative coping items. Positive items were generated from seven different subscales from the original RCOPE: spiritual connection, seeking spiritual support, religious forgiveness, collaborative religious coping, benevolent religious appraisal, religious purification, and religious focus. The seven negative items originate from five different subscales: spiritual discontent, punishing God reappraisal, interpersonal religious discontent, demonic reappraisal, and reappraisal of God's power. For a further discussion of validity and reliability see Abu-Raiya \& Pargament (2014).

\subsection{Religiosity Index (RI).}

Developed by Piedmont and part of the ASPIRES, these items assess religious involvement and commitment (Brown, Chen, Gehlert, \& Piedmont, 2013). Participants are asked to rate themselves on Likert-type items including how often they: read the bible ( 1 "never" to 7 "several times a week"); read religious literature (1 "never" to 7 "several times a week"); pray (1 "never" to 8 "daily"); and, attend religious services (1 "never" to 5 "quite often"). The Religiosity Index is computed by transforming item-responses into z-scores and then obtaining the sum of the standardized scores. In U.S. samples of adults and college students, scores on the Religiosity Index have demonstrated alpha reliabilities over .70 (Brown, et al., 2013).

\subsection{Spiritual Transcendence Scale (STS).}

Developed by Piedmont and part of the ASPIRES, this 24-item scale operationalizes spiritual transcendence as an individual's innate capacity to construe a broad sense of personal meaning (Brown, et al., 2013). The STS consists of three subscales: Universality, a belief in the unity and purpose of life; Prayer Fulfillment, an experienced feeling of joy and contentment that result from prayer and/or meditation; and, Connectedness, a sense of personal responsibility and connection to others. Items are rated on a Likert-type scale ranging from 1 "strongly agree" to 5 "strongly disagree." Reliability and validity information for self and observer forms are given in Brown, et al. (2013). Scores on these scales have also been shown to predict a variety of related spiritual constructs and a number of psychologically salient outcomes (e.g., stress experience, well-being, and attitudes towards sexuality (Brown, et al., 2013). 


\section{Procedure}

\subsection{Self-Report Data}

Each of the participants completed self-ratings on all measures. The order of the measures was randomized based on month of birth to reduce order effects and to distribute fatigue effects evenly across measures. Participants received uniform instructions to complete the questionnaires in a relatively quiet, comfortable place free from distraction.

\subsection{Recruitment and Data Collection Strategy}

The Administrative Courts of the State of Maryland, USA provided a list of 5067 names, selected randomly from the population of divorce litigants for cases filed in the Circuit Court for Howard County, Maryland, within the prior year. Letters of invitation to participate in the study were mailed to each individual soliciting participation in the study. The letters identified the principal investigator and a website where each subject could complete the items contained in the study. Letter recipients were advised that their responses would be anonymous and aggregated.

Individuals who participated in the study accessed it over the Internet by visiting a designated website hosted by SurveyMonkey.com. All entries were encrypted to maintain security in collection of responses. The first page viewed by each participant was an informed consent form describing the purpose of the study, the parameters of its anonymity and confidentiality, contact information for the study administrators, a statement that participation in the study could be terminated at any time, and a statement that this project had been reviewed and approved by the Human Subjects Review Committee at a mid-sized university with the committee's direct phone number.

\subsection{Design and Analysis}

\subsubsection{Predictive Role of Numinous Constructs Versus Personality.}

A central issue in the study of numinous constructs is whether they add to the understanding of psychosocial outcomes above and beyond what is already explained by established psychological constructs. Demonstration of the incremental validity of numinous constructs versus the robust construct of personality would support the idea that religiosity and spirituality, as measured, offer unique contributions to positive adaptation to stress over and above any predictive contribution made by personality. A lack of incremental validity of the numinous scales would imply that these provide no additional understanding of positive adaptation to stress.

To assess the predictive role of numinous constructs versus personality, hierarchical multiple regression analyses were conducted using the psychosocial variables of positive adaptation to stress as criterion. Predictor measures were the Spirituality Transcendence Scale, the Religiosity Index, and the Bipolar Adjective Rating Scale of the domains of the FFM.

\subsubsection{Predictive Value of Religious Coping to Adaptation to Stress.}

Correlations among positive religious coping and negative religious coping with TAS and the variables making up TAS were obtained. To isolate and assess the predictive roles of positive religious coping and negative religious coping to TAS, a hierarchical multiple regression analysis was conducted. Predictor measures were the negative and positive domains of the Brief RCOPE. Using TAS as a criterion variable, positive religious coping and negative religious coping were entered as a block.

\section{Result}

6.1 Hypothesis 1: Domains of Spirituality and Religiosity Would Contribute to Variance In Positive Adaptation To Stress.

Table 1 reveals correlations among the domains of spirituality and religiosity and religious coping and the outcome variables.

Table 1. Correlations among Spirituality Domains and Religiosity with Religious Coping, and Adaptation Outcome Measures.

\begin{tabular}{lccccl}
\hline & Prayer & Universality & Connectedness & Total STS & Religiosity \\
\hline Relig Coping & & & & & \\
Pos Rcope & $.58^{* * * * *}$ & $.16^{* * * *}$ & .06 & $.38^{* * * * *}$ & $.76^{* * * * *}$ \\
Neg Rcope & $-.09^{*}$ & $-.12^{* * *}$ & .07 & -.07 & $.15^{* * *}$ \\
Adaptation & & & & & \\
SRG & $.38^{* * * * *}$ & $.17^{* * * * *}$ & .05 & $.27^{* * * * *}$ & $.36^{* * * * *}$ \\
Hope & $.26^{* * * * *}$ & $.19^{* * * *}$ & .03 & $.23^{* * * * *}$ & .07 \\
SWL & $.31^{* * * * *}$ & $.18^{* * * * *}$ & .02 & $.24^{* * * * *}$ & .07 \\
TAS Total & $.43^{* * * * *}$ & $.24^{* * * *}$ & .04 & $.33^{* * * * *}$ & $.23^{* * * * *}$ \\
\hline
\end{tabular}


Note. $N=$ 501. Relig Coping $=$ Religious Coping. Pos RCOPE $=$ Positive Religious Coping. Neg RCOPE $=$ Negative Religious Coping. Adaptation $=$ Adaptation to Stress. SRG = Stress Related Growth. SWL = Satisfaction with Life. TAS Total $=$ Total Adaptation to Stress (Composite Outcome Variable). $* p<.05 ; * * p<.01 ; * * *<.001$, two-tailed.

As shown, prayer fulfillment, universality, and total transcendence are positively and low to moderately correlated with the outcome variable, TAS, and its elements, stress related growth, hope, and satisfaction with life. Clearly, individuals from this data set who felt that they had a close relationship with some ultimate being and tended to view their life as a larger plan seemed to find more stability in dealing with marital separation or divorce in their lives. Connectedness, on the other hand, had no relations to the coping and outcome variables suggesting that this aspect of spirituality which centers on the types of relationships which individuals have with other people, living and dead, does not seem to impact coping ability with stress relating to separation and divorce in their lives. In order to better identify the unique contribution of the spiritual and religious constructs to adaptation to stress, a multiple regression analysis was performed. The regression analysis tested whether the spirituality and religiosity domains as measured by the STS Scale, were significantly related to the outcome composite variable, TAS. The composite adaptation to stress variable was used as a criterion variable and the spirituality scale scores and total religiosity scores were entered simultaneously into the equation. After entering the spirituality and religiosity scores as one block, a significant model occurred, $R^{2}=.19, F(4,497)=28.16, p<.001$. The pattern of findings is presented in Table 2.

Table 2. Multiple Regression Analysis for Spirituality and Religiosity Predicting Positive Adaptation to Stress.

\begin{tabular}{lrccrc}
\hline Variable & $B$ & $S E B$ & $\beta$ & $t$ & $p$ \\
\hline Prayer Fulfillment & .085 & .01 & .44 & 7.53 & .001 \\
Universality & .006 & .01 & .04 & .85 & .398 \\
Connectedness & -.006 & .01 & -.03 & -.71 & .479 \\
Religiosity & -.012 & .01 & -.04 & -.86 & .392 \\
\hline
\end{tabular}

Note. $N=502$.

As can be seen, a significant effect was found for prayer fulfillment, $\beta=.44, t(497)=7.53, p<.001$. It is apparent that the aspect of spirituality which relates to one's ability to find an emotionally sustaining relationship with a transcendent being that is most clearly related to one's sense of adaptation.

\subsection{Hypothesis 2: Religious Coping Would Explain Significant Variance Over And Above Personality In Predicting Positive Adaptation To Stress.}

It was expected that positive religious coping would be positively related and negative religious coping would be negatively related to positive adaptation to stress. Table 3 reports correlations among the religious coping scales with the outcome variables. As shown in Table 3, the expected pattern of results was found.

Table 3. Correlations among Religious Coping with Outcome Variables.

\begin{tabular}{lllll}
\hline & SRG & Hope & SWL & Total Adaptation \\
\hline RCOPE & & & & \\
Positive RCOPE & $.55^{* * *}$ & .01 & -.00 & $.25^{* * *}$ \\
Negative RCOPE & .08 & $-.29^{* * *}$ & $-.35^{* * *}$ & $-.25^{* * *}$ \\
\hline
\end{tabular}

Note. $N=$ 493. RCOPE=Religious Coping. Positive RCOPE = Positive Religious Coping. Negative RCOPE = Negative Religious Coping. SRG = Stress Related Growth. SWL $=$ Satisfaction with Life. Total Adaptation = Positive Adaptation to Stress (Composite Outcome Variable). $* * * p<.001$.

In order to better isolate the unique contribution of the coping constructs of positive and negative religious coping to the outcome variable, a hierarchical multiple regression analysis was used. The regression analysis tested whether the coping domains as measured by the Religious Coping Scale would be significantly related to the criterion variable, positive adaptation to stress. In order to test this, the composite adaptation to stress variable was used as a criterion variable and positive religious coping and negative religious coping were entered simultaneously into the equation. After entering the religious coping scores as one block, a significant model emerged. The pattern of findings is presented in Table 4. 
Table 4. Multiple Regression Analysis for Positive and Negative Religious Coping, Predicting Positive Adaptation to Stress.

\begin{tabular}{lccccc}
\hline Variable & $B$ & $S E B$ & $\beta$ & $t$ & $p$ \\
\hline Pos RCOPE & .050 & .01 & .16 & 4.36 & .001 \\
Neg RCOPE & -.078 & .02 & -.14 & -3.68 & .001 \\
\hline
\end{tabular}

Note. $N=487$. Pos RCOPE $=$ Positive Religious Coping. Neg RCOPE = Negative Religious Coping.

As can be seen, significant effects were found for positive religious coping, $\beta=.16, t(483)=4.36, p<.001$ and negative religious coping, $B=-.14, t(483)=-3.68, p<.05$.

\section{Discussion and Implications for Mental Health Providers}

The results of this study provide empirical evidence which suggests a unique contribution of spirituality, religiosity, and religious coping in one's adaptation to stress. The results also enhance a growing body of evidence that suggests the unique and practical roles of numinous traits in the human mental and physical systems. Mental health professionals offer unique, varied, and broad interventions in helping individuals adapt positively to stress associated with separation and divorce by explicitly focusing on the exploration, establishment, and implementation of individuals' resources. This approach should incorporate a view that spirituality, religiosity and religious coping play active roles in adaptation to stress associated with marital disruption. Health providers may need to accommodate and be cognizant of their clients' spiritual and religious ways of being which may have implications for coping skills, defense styles, and overall adaptation to stress. Caution should be used, however, to ensure that it is the client's desire to venture into realms of spiritual or religious inquiry, not the health providers.

Prayer fulfillment was the major spirituality predictor of adaptation to stress. Quintessentially, it is one's relationship with a transcendent reality or being that seems to create a positive space in one's life. Trying to fill this space with a transcendent realty of one's understanding may be the key to adaptation to stress when coping with separation and divorce. Praying, reading the Bible, and attending church are part of what one may do in relating to a transcendent being, but creating a relationship with the transcendent appears to be key. While universality correlates with the outcome variable, through regression analysis we see that it is really prayer fulfillment that contributes to variance in adaptation to stress. It is that aspect of spirituality that relates to one's ability to find an emotionally sustaining relationship with a transcendent being that is most clearly related to one's sense of adaptation to stress. Notably, Slater, Hall, and Edwards (2001) suggest that the prayer fulfillment scale of the STS really seems to capture what spirituality actually is and that the other scales are less centrally related to "true" spirituality.

For many, incorporating spiritualty into one's coping with stress involves a re-framing of life and of one's connection to a transcendent being. Practices which can be taught to move clients into a more "spiritual realm" include methods of mindfulness, as well as meditation, Tai Chi, Yoga, and Reiki (McKernan, 2007). Learning ways to pray have also been shown to be useful (Abu-Raiya \& Pargament, 2014) as have forms of gratitude intervention. Data appears to support the notion that spiritual and religious variables are much more amenable to change and intervention than personality. This is of considerable importance to counselors who are trained to intervene at the intersection of spiritual and coping dimensions. Being able to focus in on spiritual issues and to work with people on their spiritual agenda may be a useful intervention approach for helping people thrive and adapt better after marital dissolution.

\section{Limitations of This Study}

This study examined individuals in one moment of time. It would be useful in discerning how predictive the variables studied are to conduct a longitudinal study. This study lacked a control group (e.g., individuals who are not divorcing). It is likely that a self-reporting bias played a role in some respondents as it is expected that respondents would want to demonstrate that they adapted well to their divorce. In addition, all subjects were going through or had recently concluded a legal divorce procedure. Individuals going through a divorce may bring unique and confounding attributes associated with their disunion. Divorce can be a momentary traumatic event or a chronic ongoing circumstance. This was not addressed in this study. This study lacked assessments of different types of psychosocial mechanisms which may have been promoting people toward growth. Social involvement and family histories were not measured in this study. This study does not address why people change or why they experience positive adaptation to stress.

\subsection{Future Research}

An area for future research should include the study of cohort effects. To what extent do the views of society, one's community, friends, and family impact the way in which one adapts to separation and divorce? Future research should explore to what extent the variables measured herein are impacted by factors of time? Are we measuring something unique, do all people simply heal over time, and is it a question about whether some people heal quicker than others? 
Other factors which may be worth exploring include length of marriage, prior marriages, or age at marriage and divorce. Although we know that separation and divorce have been rated high on the list of most stressful events an individual can experience, an impact of events scale would establish a clearer connection between conclusions drawn and impact actually experienced by participants. Finally, more research is needed regarding the cultural factors which influence divorce and how improved socio-economic environments might develop mechanisms for enhancing marital relationships and reduce heightened levels of divorce.

\section{References}

Abu-Raiya, H., \& Pargament, K. I. (2014). Religious coping among diverse religions: Commonalities and divergences. Psychology of Religion and Spirituality. Advance online publication. http://dx.doi.org/ 10.1037/a0037652

Brown, I., Chen, T., Gehlert, N., \& Piedmont, R. (2013). Age and gender effects on the Assessment of Spirituality and Religious Sentiments (ASPIRES) scale: A cross-sectional analysis. Psychology of Religion and Spirituality, 5(2), 90. http://dx.doi.org/10.1037/a0030137

Dein, S., Cook, C., \& Koenig, H. (2012). Religion, spirituality, and mental health: Current controversies and future directions. Journal of Nervous \& Mental Disease, 200(10), 852-855. http://dx.doi.org/ 10.1097/NMD.0b013e31826b6dle

Diener, E., Emmons, R., Larsen, R., \& Griffin, S. (1985). The satisfaction with life scale. Journal of Personality Assessment, 49(1), 71-75. http://dx.doi.org/ 10.1207/s15327752jpa4901_13

Finn, A., \& Wang, L. (2014). Formative vs. reflective measures: Facets of variation. Journal of Business Research, 67(1), 2821-2826. http://dx.doi.org/ 10.1016/j.jbusres.2012.08.001

Hodge, D. (2005). Spiritual lifemaps: A client-centered pictorial instrument for spiritual assessment, planning, and intervention. Social Work, 50(1), 77-87. http://dx.doi.org/ 10.1093/sw/50.1.77

Krumrei, E., Mahoney, A., \& Pargament, K. (2011). Spiritual stress and coping model of divorce: A longitudinal study. Journal of Family Psychology, 25(6), 973-985. http://dx.doi.org/ 10.1037/a0025879

Kulik, L., \& Heine-Cohen, E. (2011). Coping resources, perceived stress and adjustment to divorce among Israeli women: Assessing effects. The Journal of Social Psychology, 151, 5-30. http://dx.doi.org/ $10.1080 / 00224540903366453$

Lee M., Nezu, A., \& Nezu, C. (2014). Positive and negative religious coping, depressive symptoms, and quality of life in people with HIV. Journal of Behavioral Medicine, 37(5), 921-930. http://dx.doi.org/ $10.1007 / \mathrm{s} 10865-014-9552-\mathrm{y}$

Mazzotti, E., Mazzuca, F., Sebastiani, C., Scoppola, A., \& Marchetti, P. (2011). Predictors of existential and religious well-being among cancer patients. Supportive Care in Cancer, 19(12), 1931-1937. http://dx.doi.org/ $10.1007 / \mathrm{s} 00520-010-1033-4$

McCrae, R., \& Costa, P. (1987). Validation of the five-factor model of personality across instruments and observers. Journal of Personality and Social Psychology, 52(1), 81. http://dx.doi.org/ 10.1037//0022-3514.52.1.81

McKernan, M. (2007). Exploring the spiritual dimension of social work. Spirituality and social work: Selected Canadian Readings, 93-110. http://dx.doi.org/ 10.1300/j377v26n01_04

Miller, W., \& Thoresen, C. (2003). Spirituality, religion, and health: An emerging research field. American Psychologist, 58(1), 24. http://dx.doi.org/ 10.1037/0003-066x.58.1.24

Musai, M. (2011). The relationship between divorce and economic-social variables in Iran. British Journal of Arts and Social Sciences, 1(2), 89-93. http://dx.doi.org/ 10.6007/ijarbss/v4-i3/740

Pargament, K., Feuille, M., \& Burdzy, D. (2011). The Brief RCOPE: Current psychometric status of a short measure of religious coping. Religions, 2(1), 51-76. http://dx.doi.org/ 10.3390/rel2010051

Park, C. (2005). Religion as a meaning - making framework in coping with life stress. Journal of Social Issues, 61(4), 707-729. http://dx.doi.org/ 10.1111/j.1540-4560.2005.00428.x

Pienaar, J. (2008). 12 Skeleton key or siren song: Is coping the answer to balancing work and well-being? in Naswall, Hellgren \& Sverke (Eds) The Individual In the Changing Working Life, Cambridge University Press, 235-257. http://dx.doi.org/ 10.1017/CBO9780511490064.012

Premsingh, J., \& Philip, S. (2014). A study on the increasing divorce rate in Kerala. Journal of Humanities and Social Science, 19(6), 58-60.

Roesch, S. C., Rowley, A. A., \& Vaughn, A. A. (2004). On the dimensionality of the Stress-Related Growth Scale: One, 
three, or seven factors, Journal of Personality Assessment, 82(3), 281-290. http://dx.doi.org/ 10.1207/s15327752jpa8203_04

Schweitzer, R., Greenslade, J., \& Kagee, A. (2007). Coping and resilience in refugees from the Sudan: a narrative account. Australian and New Zealand Journal of Psychiatry, 41(3), 282-288. http://dx.doi.org/ 10.1080/00048670601172780

Slater, W., Hall, T. W., \& Edwards, K. J. (2001). Measuring religion and spirituality: Where are we and where are we going? Journal of Psychology and Theology, 29(1), 4-31.

Snyder, C. R., Sympson, S. C., Ybasco, F. C., Borders, T. F., Babyak, M. A., \& Higgins, R. L. (1996). Development and validation of the State Hope Scale. Journal of personality and social psychology, 70(2), 321. http://dx.doi.org/ 10.1037//0022-3514.70.2.321

Tashiro, T., Frazier, P., \& Berman, M. (2006). Stress-related growth following divorce and relationship dissolution. Handbook of Divorce and Relationship Dissolution, 361-384. http://dx.doi.org/ 10.4324/9781315820880

Tedeschi, R., \& Calhoun, L. (2004). Posttraumatic growth: Conceptual foundations and empirical evidence. Psychological inquiry, 15(1), 1-18. http://dx.doi.org/ 10.1207/s15327965pli1501_01

Wong, P. (2010). Meaning therapy: An integrative and positive existential psychotherapy. Journal of Contemporary Psychotherapy, 40(2), 85-93. http://dx.doi.org/ 10.1007/s10879-009-9132-6

(cc) Br

This work is licensed under a Creative Commons Attribution 3.0 License. 